\title{
The Dynamics of Ethnicity in a Multicultural Society
}

\author{
Dr. Kibiwott P. Kurgatt
}

\begin{abstract}
Ethnicity is sometimes one of the misunderstood cultural aspects of national heritage in Africa. The mere mention of the term 'ethnicity' or 'ethnic origin' is apt to elicit negative reactions, basically because only one facet is assumed, namely 'ethnocentricity', or to use a less anodyne term, 'tribalism'. Yet there are many other positive facets to ethnicity. For example, ethnicity can be claimed, rightly so, as one aspect of national identity, which enriches Africa's national heritage(s).This paper attempts to highlight these dynamics through analyzing how one community, namely, the Nandi, manifests its ethnicity its social construction of reality, the differences in intra-ethnic identities that separate them from their immediate 'cousins' as well as other neighbors, namely, the Maasai and Luo and the Kenyan nation as a whole. It is hoped that the answers to the above will help us to positively harness ethnic diversity to create a multicultural society at ease with itself.
\end{abstract}

\section{Introduction}

First of all, this paper is in many ways an exploratory paper which is part of ongoing research on ethnic relations that attempts to bridge the gap between theorization of the concept of ethnicity on the one hand and what is presented by the media and politics on the other. This paper is also borne out of suggestions for further research on perceptions of identity by members of a group - particularly the study of symbolic and non-symbolic markers and their perceived role in identity continuation suggested by Edwards (1985). Although his suggestions were mainly concerned with language and identity in a multicultural setup, it is still relevant to social scientists interested in studying the dynamics of ethnicity in the contemporary world. This is particularly relevant in Africa where the modern scientific culture and the new concepts engendered by democratization have sometimes brought out sharp divisions between communities who have to look beyond their ethnic perceptions of society and rise up to the new challenges of nationhood. Moreover, the need to analyze the dynamics of ethnicity has also been suggested by Ogot (1996). While citing the observations of Spear and Waller (1993), who analyzed issues surrounding Maasai identity (for example, the shift from struggle for control over cattle to control over land), Ogot suggests that studies could be carried out to show what being a member of a community (Kikuyu, Luo, Kalenjin, etc) means. Secondly, it needs to be stated at the onset that this paper seeks to problematize the issues raised by contemporary ethnic identity through looking at it from a different angle and ultimately, hopefully, broaden and deepen our understanding of the dynamics of ethnicity. Thirdly, I wish to emphasize that by looking specifically at the way the Nandi express or look at their ethnic identity, I am in no way saying that they are a unique community whose socio-political outlook is drastically different from other Kenyan communities. The contention here is that modern living and cross-cultural contact have contributed to the Nandi's construction of their social reality in a unique way due to the past history of the community. 


\section{Rationale}

In seeking to broaden and deepen our understanding of the dynamics of ethnicity by revealing persistent as well as dynamic markers of ethnicity and the motivation behind the persistence and dynamism, it is hoped that avenues for handling ethnic diversity in modern African states will become less blurred. For instance, there are three avenues for decision-making that really come to mind but each of which is fraught with dangers. One suggestion is to emphasize cultural differentiation as an aspect of national identity. This, however, at the worst may lead to ethnic differences becoming embedded in structures and institutions in ways that can lead to polarization of ethnic groups. The other suggestion is to deny ethnicity. This can be done, it has been suggested, by reifying the concept of a nation. This, however, seems to be a poor solution as we will miss so much of the diverse historical experience that really make up a rich source of Africa's cultural heritage. Moreover, this does not take into consideration the persistence and dynamism of some markers of ethnic identities in communities regardless of 'modernization' and the creation of the modern scientific states or nations.

The third suggestion is emphasis on cultural diversity. This seems the most likely candidate, as in my view, appreciation of others can be used to underpin national policy so that we can create structures that are democratic while eliminating the dictatorship of majoritarianism.

\section{Theoretical basis}

The theoretical underpinning of this paper is that of social construction. What this means is that as social beings, all human existence is basically bound to particular social locations. As such, ethnicity can be viewed as a social institution that is, as one social scientist describes, an alibi which can be an instrument for our liberation. In other words, depending on how one views his/her social role as expressed in ethnic identity, an individual or group may choose to be 'lost', so to speak, in some society, by subsuming his individuality in the society. This can happen if a person or group chose to play social roles blindly. However, should one play it knowingly, it can become a way of making sound decisions. What this means is that ethnicity as a social reality may have a positive or negative impact on a wider society e.g. a nation, depending on whether individuals or groups within it plays their social roles blindly or knowingly.

Another aspect that underpins this paper is the departure from the view by some social scientists that ethnic identity is stable and fixed. Here, ethnicity is seen as a function of changing times; that it is "flexible and shifting, emerging and changing in response to contexts in which it is expressed... (so that)... certain situations call for the expression of a particular identity, while other contexts make it appropriate to submerge, or forget or even deny the same reality" (Tessler et al 1973:42). 


\section{Markers of Ethnic Identity}

Social scientists have noted several aspects around which communities in Africa have constructed their group identities. These are rituals, language and the idea of a homeland (Tessler et al 1973). Firstly, community rituals such as rites de passage marriage, circumcision, death and burial, signified a community's identity. These were also sometimes used to differentiate one community from others. Secondly, language was seen as a 'ready and powerful symbol of ethnic identity' (Tessler et al 1973) particularly in a multilingual environment. Thirdly, place of habitation, particularly the so-called 'ancestral land' which a majority of individuals or group has inhabited just before the arrival of the colonialists is another symbol of identity.

Even currently, by and large, people who move from their ancestral land to urban areas in search of employment for instance, usually still have an attachment in the form of a house in some family land, which they call home. Consequently, land bought and owned in urban areas is seen as an investment rather than a home. Even an individually owned residential plot with a house in the urban area is not really seen as a 'home' but a 'residence' (Even though these two words are basically synonyms!). A person is more likely to answer the question "Where do you come from?" with an answer like "from Western, Rift Valley, Nyanza, and so on or may choose to ask you to clarify whether you mean home or where s/he lives. However, I believe this demarcation between town and country is getting blurred with the rising population and pressure on limited land in rural (ancestral) areas.

Apart from the above, however, there are more latter day symbols that may be seen as ethnic as well as cross ethnic. These include issues like contemporary political loyalties and historical experience (pre- colonial, colonial and post colonial). These markers or symbols feature in the construction of the social realities of the group investigated. These in my view are some of the symbols that have not been analyzed thoroughly and yet probably form the germ of future national identities. In the foregoing analysis of Nandi identity below, therefore, all these symbols are revisited to see to what extent they are prevalent in the Nandis as well a as other community's construction of identity.

\section{The Nandi: A brief historical background}

The Nandi community, as we know it, is part of the larger socio-political grouping called the Kalenjin who speak dialects, which have varying degrees of mutual intelligibility. Politically, the Kalenjin may be seen as a grouping of communities in much the same way as we would look at the Luhya, the Miji Kenda or the so-called 'Gema' communities. This (Kalenjin) group has also shared, to a large extent, the same political loyalty from the 1940s to date, though this has been disputed by some of the subgroups. The target of the present research, namely the Nandi, for example, sometimes like to regard themselves as unique from the larger Kalenjin group because they had a different immediate pre-colonial experience, namely, ten years (18951905) of armed resistance to colonial invasion and having had the longest detained person in Kenyan history, the orgoiyot (chief diviner) Parserion arap Manyei. The 
Nandi also prefer to be seen as 'independent-minded'. For example, they like to be associated with those public figures from the community, namely, the late Jean Marie Seroney (First Member of Parliament for Nandi), the late Bishop Alexander Muge (the first Nandi Anglican Bishop), Samuel Arap Ng'eny, the former Deputy Speaker of the Kenyan National Assembly and lately, Kipruto arap Kirwa (presently the Minister for Agriculture), who have been described as independent-minded.

\section{Markers of Nandi Ethnic Identity}

\section{a) Historical experience}

In this instance, there are two aspects that are most prevalent as markers of Nandi ethnic identity. The first one is rooted in the pre-colonial period- their resistance to colonial invasion (1895-1905), which, to a large extent, is seen as similar to the resistance to colonialism in the 1950s. This is seen as a crucial marker of Nandi identity especially in differentiating themselves from their immediate 'cousins' (particularly the Tugen and Keiyo). Nandi resistance to colonial rule has been tackled many times and it suffices here to just say that the present population still associates with this. At the beginning of the writing of this paper, it was thought that this perception was sometimes overrated and that it was probably associated with the older generation. However, this seems to be seen by the younger generation as the most crucial aspect of Nandi identity (courageous was one common definition they gave).

The second marker of Nandi identity is one of political marginalisation and frustration of what they regard as their genuine political leaders. With respect to this, it comes out that the Nandi generally do not regard themselves as part of the mainstream political establishment. This is notwithstanding the fact that some of the positions in government have been held by some Nandis (for example, Joseph Letting, former Head of the Civil Service and Ambassador Bethuel Kiplagat, former Permanent Secretary for Foreign Affairs and Dr. Sally Kosgei, former head of the Civil Service). However, some of these people are seen more as either 'tokens' or 'sellouts' to the ruling elite. This frustration is perceived as having been experienced by what the community consider as people with leadership that transcended Kalenjin ethnic issues (the late Jean Marie Seroney, former Deputy Speaker and long time member of Parliament, on constitutionalism, the late bishop Alexander Muge on Church-State relations and presently Kipruto arap Kirwa on human rights and democracy). Such experience has served to reenforce the view held by many Nandi people that the present elite in political power see them as only 'useful' up to a certain extent beyond which they are expendable.

\section{b) Cultural heritage}

Cultural markers that were found are in three realms, namely, in rituals, sociopolitical organization and what I have clumsily termed socio-cultural outlook. These are seen as markers that, in the main, differentiate the community from 
others. With respect to socio-cultural outlook, the community regards the Luo as culturally different notwithstanding their common Nilotic heritage. On closer examination, it seems that the difference here is seen to be with respect to the ritual of circumcision. However, it should quickly noted here that the Nandi do not regard this as a crucial factor that prevents them from having any relationships with the Luo. On the other hand, the Nandi consider the Maasai as their 'equals' with regard to both socio-cultural identity and socio-political organization. This again is surprising given the fact that the Kiruogindet (judge) is an institution they originally shared with the Luo (ruoth) and that the institution of orgoiyot (seer/ diviner) was essentially a latter day ( $19^{\text {th }}$ century) borrowing from the Maasai; an institution with which the community has had a love and hate relationship. For example, the Nandis clubbed one of the first diviners, Kimnyolei, to death presumably because they felt he was not making the correct divination before the warriors went to war. However, I believe the institution had as much to do with suspicion of the unprecedented powers the institution of orgoiyot seems to have assumed in the lives of the Nandi as with failure to correctly predict the outcome of military expeditions. At the time, the institution seems to have been equated with witchcraft (witches and wizards were ritually clubbed to death when they became a social nuisance to the community).

\section{c) Homeland}

The Nandi identify themselves as the people inhabiting the three districts, Nandi, Uasin Gishu and Trans Nzoia in the Rift Valley Province of Kenya. Of these three districts, the first two are seen as essentially Nandi districts. (This is perhaps why a section of the community felt a sense of resentment during the sale (by LONRHO, a multinational corporation spanning East and Southern Africa) of land in the Uasin Gishu District on a 'willing buyer, willing seller' basis in the late 1990s). Most Nandi people feel comfortable developing homes in the two districts. Urban areas in these two districts are increasingly dotted with homes of the Nandi. However, owning some piece of land in Nakuru, Nairobi, or Kisumu for instance would result in this land being used for commercial purposes or as residential premises for a Nandi employed in these towns, with a potential for-sale-notice. It is not surprising for a Nandi living in his town of residence in Kisumu to say that s/he comes from Nandi or Uasin Gishu rather than Kondele (a suburb of Kisumu).

\section{d) Political alliances}

In terms of political alliances, the Nandi do not really specify what groups would be more acceptable as allies as they feel that democracy can be fostered on the basis of issues that transcend ethnic alliances (though they acknowledge that contiguous communities are likely candidates). By and large, the Nandi feel that alliances can be fostered with like-minded individuals and /or communities. Particularly noted is the fact that a number of the Nandis interviewed stressed that individuality should be recognized as a factor in the creation of social realities. This means that it is sometimes necessary to hold individuals rather than the communities they come from, as responsible for decisions that affect the public. This aspect (individuality) can be taken to mean that individuals should see themselves as capable of making decisions based on their own understanding of 
their place in the wider society rather than the ethnic group they belong and that these decisions essentially ought to be cross-ethnic.

\section{e) Language}

As observed earlier, language is seen as one symbol that communities may choose as an aspect of ethnic identity in a multilingual or multicultural setting. Language-wise, the Nandi see their language as an expression of diversity rather than of difference. They feel that African languages ought to be taught in educational institutions, as they are useful in exposing Kenyans to the diversity of their linguistic heritage. In comparison, other communities see language as markers of ethnic identity; as carriers of indigenous knowledge and traditions. Both the Nandi and other communities, however, hasten to note that different languages can be potentially divisive as they can serve as a marker of exclusivity if misused in a multilingual environment. However, if used positively, they are seen as potential carriers of national ideals at the grassroots level.

\section{f) Intra-ethnic and cross-ethnic identities}

The third question, which this paper set out to answer, was the question of whether differences between the Nandi and their immediate cousins are reflected in the way other groups in the communities like the Mt Kenya Bantu cluster ('Gema') and the Luhya may differentiate themselves. The perceived difference between the Nandi and their immediate 'cousins' (particularly, the Tugen and Keiyo) lie in their worldview that goes beyond their sub-ethnic borders. Here, the Nandi consider themselves as more outward- looking and more open-minded and 'accommodating' in their relationship with other communities. The other community they see as sharing this trait is the Kipsigis.

With respect to other Kenyan communities, there were no major differences except in the case of the Kikuyu, who like the Nandi, seem to regard their participation in the struggle for independence as one difference between them and the Meru and Embu. Issues of land deprivation is also shared between the Nandi and the Kikuyu as they feel they lost more land than their neighbouring 'cousins', during the colonial period (except the Kipsigis who lost land which was eventually turned to tea estates). Otherwise one gets the feeling that all these 
communities show a sense of wanting to belong to a larger community that is ideally multi-ethnic.

\section{Summary}

Several things seem to have emerged in the attempt to analyze the various symbols of ethnic identity. One factor that came out which deserves more attention is that of historical experience. This is seen as an issue of identity, which can determine how other communities could forge political alliances. For instance, the Luo perceive marginalization of the community particularly during the Kenyatta era (the first post-colonial government led by Mzee Jomo Kenyatta as president) as an experience that identifies them with those who have perceived themselves as having been marginalized. What does not come out however, is which particular communities are perceived by the Luo as having had this experience. Nevertheless, the interesting thing to note is that this potential alliance is regarded as cross ethnic. It seems, therefore, that this is really a pointer to shared experience as a factor that could be used to create a sense of national identity among the diverse communities of Kenya. For instance, one factor derived from historical experience that has been successful as a symbol of Tanzania's nationhood is the fight for independence. This is seen as a national endeavor rather than one in which one or a few ethnic groups were involved. This is a potentially powerful symbol for Kenya too. In the 1960s and 1980s, one or two communities have, it seems, seen this issue of the struggle for independence as an exclusive undertaking. Let it be clear, however that neither for a single instance is revisionism being suggested. On the contrary, communities should be given their due acknowledgment for their place in the history of liberation. However, this should not be used, as noted earlier, for the furtherance of an (ethnic) identity to the exclusion of others.

Related to the issues of forging alliances on the basis of shared experience is the issue of perceived trustworthiness (or lack thereof!) of other communities. Again, these kind of 'potential' alliances (some are already in existence) may serve to exclude other communities, as the basis of such alliances is that some communities rather than others are perceived as trustworthy. Moreover, the bases of distrust of certain communities (as thieves, unprincipled, etc) seem to have roots in prejudices that have developed over time and whose flames were fanned by colonialism as a strategy to divide and rule the indigenous population. However, one may argue that alliances are a fact of life, and that they, so long as they are not formed on the basis of prejudice, may be seen as valid in the same way as individuals forge friendship-through choice.

Another aspect that is a possible candidate is for discerning (a) symbol (s) of identity is culture. However, this did not yield much as it was found that there were no markers derived from indigenous cultures, which could be seen as national enough. Perhaps the National Music and Drama Festivals should be 
seen as arenas where various traditional songs, for example, develop to become truly descriptions of national culture rather than a platform for parading cultural differences. This could develop in the same way as in Tanzania where ngomas (traditional dances) have evolved to become distinctly Tanzanian through borrowing from the various ethnic communities.

Lastly, the other aspect that we noted earlier is that of the individual's place in the construction of social realities. From the Nandi perspective, though the individual is acknowledged as belonging to some social milieu, $\mathrm{s} / \mathrm{he}$ is recognized nevertheless as having a potential to make decisions that go beyond his/her social (or ethnic) 'cocoon' (to which some individuals are sometimes satisfied with 'losing' themselves). In the Nandi language, for example, we have a saying that, "Even though a rat may be bad, it still belongs to the house it lives in". This has sometimes been misconstrued to mean that even though an individual acts contrary to what is considered as acceptable practice, his/her actions are forgivable because s/he is 'ours'. In my view, however, this saying really means that a society can be held responsible for an individual's actions, if it offers refuge to such an individual who is acting contrary to accepted standards (particularly where the standard are recognizes as cross-ethnic). The upshot of this is that societies have a responsibility to 'discipline' its errant members to the extent that they have acted contrary to cross-ethnic norms. It follows from this that individuals acting contrary to the norms of a wider society should not hide behind his/her ethnic society (hence 'lose' his/her freedom) whereas society should not protect individuals (hence 'lose' its freedom). What this comes to is that individuals should be able to make informed decisions while acknowledging their membership of a community as well as recognizing the necessity of belonging to a wider society.

\section{Conclusion}

In conclusion, what was emphasized at the beginning is again reiterated here, namely, that this paper sought to problemize the issue of ethnicity by broadening our understanding of its markers and the motivation for the dynamism that these markers exhibit. All it needs to be said is that, even though the symbols or markers of identity that have been examined above carry with them a danger of creating exclusivity, the germ of appreciation for diversity inherent in them can serve as the basis for forging new multicultural symbols. This ensures that individuals or groups do not 'lose' themselves in the 'mechanisms' of an exclusive social reality through, as we said earlier, playing social roles blindly. Finally, 
98 Dr. Kibiwott P. Kurgatt

positive development in all its facets is possible if policies are formulated in such a way that it will enable us to guard against this potential danger of exclusion and institutionalization of differentiation. This can be done by consciously building structures and institutions that prize and emphasize diversity and ascribe to an open-ended policy of inclusion.

\section{References}

Berger, P.L. and Luckmann, T.1996. The Social Construction of Reality. London and Victoria. Penguin Books Ltd.

Bohannan, P and Curtin, P 1971. Africa and Africans. New York. The American Museum of Natural History.

Edwards, J. 1985. Language, Society and Identity. London. Basil Blackwell.

Murdock, G.P. 1959. Africa: Its peoples and their cultural history. New York. McGraw Hill.

Ogot, B.A. 1996. Ethnicity, Nationalism and Democracy in Africa. Maseno University. Institute of Research and Postgraduate Studies.

Tessler, M.A., O'Barr, W.M. and Spain, D.H. 1973. Tradition and Identity in Changing Africa. New York. Harper and Row.

Ungar, S.J. 1978. Africa: The People and Politics of an Emerging Continent. New York. Simon Schuster. 